\title{
Expectativas quanto às Disciplinas de Matemática no Curso de Pedagogia: a importância de ouvir os alunos
}

\author{
Expectations for Mathematics Courses in the Pedagogy Program: \\ the importance of listening to students
}

Monise Zanetti ${ }^{1}$

Rejane Siqueira Julio²

1Universidade Federal de Alfenas (UNIFAL-MG), Programa de Pós-Graduação em Educação, Alfenas, MG, Brasil.
Universidade Federal de Alfenas (UNIFAL-MG), Instituto de Ciências Exatas, Departamento de Matemática, Alfenas, MG,
Brasil. Autora correspondente: rejane.julio@unifal-mg.edu.br

Resumo: A proposta deste artigo é a realização de uma leitura, sob a ótica do Modelo dos Campos Semânticos, de falas de pedagogas iniciantes a partir de entrevistas sobre suas vivências com as disciplinas de Matemática na Educação Básica e suas expectativas quando foram cursar disciplinas de Matemática no curso de Pedagogia. Ocorreram diferentes produções de significados a partir das vivências relatadas, sendo que algumas gostavam e outras não das disciplinas de Matemática, atribuindo diferentes fatores para isso. Também ocorreram diferentes expectativas quanto às disciplinas de Matemática no curso de Pedagogia que parecem não terem sido ouvidas pelos(as) professores(as) formadores(as). Com isso, ressalta-se a importância de ouvir futuros(as) pedagogos(as) e conhecê-los(as) para que possam ocorrer interações na direção de uma ampliação de modos de produção de significados para a Matemática e as disciplinas de Matemática na Educação Básica.

Palavras-chave: Formação inicial do professor; Educação matemática; Educação básica; Formação dos profissionais da educação.

Abstract: The purpose of this article is to carry out a reading, under the perspective of the Model of Semantic Fields, of interviews with pedagogues about their experiences with the Mathematics subjects in Basic Education and their expectations when they were taking courses of Mathematics in the Pedagogy program. There were different productions of meanings from the reported experiences, some of which show liking and others not liking of the Mathematics subjects, attributing different factors for that, as well as different expectations regarding the Mathematics subjects in the Pedagogy program that seem not to have been heard by the instructors. Thus, the importance of listening to future pedagogues is emphasized in order to get to know them so that interactions can occur in the direction of an expansion of ways of producing meanings for Mathematics and Mathematics subjects in Basic Education.

Keywords: Teacher training; Mathematical education; Basic education; Training of education professionals.

Recebido em: 21/03/2020

Aprovado em: $23 / 04 / 2020$ 


\section{Introdução}

O curso de Pedagogia é caracterizado, de acordo com as Diretrizes Curriculares Nacionais para o Curso de Licenciatura em Pedagogia (BRASIL, 2005) por uma diversidade de possibilidades, como o atendimento aos mais variados níveis de Ensino (docência na Educação Infantil e nos anos iniciais do Ensino Fundamental, na modalidade Normal dos cursos de Ensino Médio e em cursos de Educação Profissional) e a atuação na área de serviços, apoio escolar e outras que preveem conhecimentos pedagógicos.

$\mathrm{O}(\mathrm{A})$ professor(a) polivalente ou pedagogo(a), de acordo com Curi (2005), além de ter que trabalhar com diferentes áreas de conhecimento, precisando saber várias disciplinas para ensiná-las, de forma interdisciplinar e contextualizada, também precisa conhecer seus(suas) alunos(as), seus interesses, suas motivações, suas dificuldades, além de gerir a sala de aula. Dentre essas disciplinas, está a de Matemática.

Como a(s) disciplina(s) de Matemática compõe $(\mathrm{m})$ a grade curricular dos cursos de Pedagogia e o currículo da Educação Básica, a formação e a prática de pedagogos(as) no âmbito da Matemática têm sido tema de crescente interesse por parte de pesquisadores, como vemos no mapeamento realizado por Fiorentini, Passos e Lima (2016). Santos e Lima (2011), por exemplo, delinearam um panorama de pesquisas na área de formação de professores de Matemática para os anos iniciais do Ensino Fundamental, a partir das análises de dissertações e teses defendidas em programas de pós-graduação da área de Ensino de Ciências e Matemática. Em suas análises, criaram as seguintes categorias que expressam temáticas de maior concentração presentes nos trabalhos analisados: formação inicial de professores, concepções dos professores, metodologias de ensino, estudo histórico, profissão docente, conhecimentos do professor e prática docente. A maioria dos trabalhos abordava mais de uma categoria, sendo as duas primeiras citadas, e os conhecimentos do professor, as categorias predominantes. As autoras apontam isso como algo importante, tendo em vista que a formação inicial de professores pode gerar efeitos em suas práticas. Essa temática também tem ganhado espaço em publicações de revistas da Educação Matemática (BORBA; CURI, 2016).

Dentro da temática formação inicial de pedagogos(as) propõe-se, neste artigo, analisar, a partir de entrevistas realizadas com pedagogas iniciantes ${ }^{1}$ - professoras com menos de cinco anos de docência -, as expectativas que elas tinham quando foram cursar a(s) disciplina(s) de Matemática do curso de Pedagogia e se elas consideraram que essas expectativas foram atendidas, enfatizando a importância de ouvir os(as) futuros(as) pedagogos(as), tendo em vista o passado que tiveram com as disciplinas de Matemática na Educação Básica e o impacto que todas essas disciplinas podem acarretar em suas práticas profissionais.

Trata-se do recorte de uma pesquisa finalizada cujo objetivo foi realizar, por meio de entrevistas, uma leitura das produções de significados das pedagogas iniciantes de São José do Rio Pardo, Estado de São Paulo, que atuam na Educação Infantil e nos anos iniciais do Ensino Fundamental, sobre suas práticas profissionais e de formação na Educação Básica e no curso de Licenciatura em Pedagogia e as relações que estabelecem entre as formações

'Estamos utilizando pedagogas porque foram entrevistadas somente professoras do sexo feminino. 
e a atuação profissional, tendo como referencial teórico o Modelo dos Campos Semânticos, abreviado por MCS ou Modelo, proposto pelo educador matemático Romulo Campos Lins (LINS, 1999, 2012).

Dessa forma, neste artigo, será abordado, inicialmente, o MCS, referencial teórico que tem embasado esta pesquisa, para, em seguida, fazer uma análise das vivências das pedagogas com as disciplinas de Matemática na Educação Básica, considerando que a formação inicia antes mesmo de elas ingressarem no curso de graduação em Pedagogia, e depois das expectativas que essas pedagogas tiveram sobre a(s) disciplina(s) de Matemática na graduação.

\section{O Modelo dos Campos Semânticos (MCS) como Referencial Metodológico de Pesquisa}

O MCS é um modelo epistemológico criado por Romulo Campos Lins (LINS, 1999, 2012), que tem como noções centrais significado, objeto e conhecimento, sendo significado tudo o que se pode e efetivamente se diz de um objeto em uma situação ou atividade. Já objeto é "[...] algo a respeito de que se [diz] algo" (LINS, 2004, p. 114); produzir significados é "[...] falar a respeito de um objeto" (LINS; GIMENEZ, 1997, p. 146). Cabe ressaltar que objeto não é algo estático, mas constituído pela produção de significados para ele.

A noção de produção de significado é fundamental neste Modelo, pois "[...] toda produção de significado implica produção de conhecimento" (LINS, 1999, p. 87) e conhecimento" [...] consiste em uma crença-afirmação (o sujeito enuncia algo em que acredita) junto com uma justificação (aquilo que o sujeito entende como lhe autorizando a dizer o que diz)" (LINS, 2012, p. 12). Para exemplificar, tanto crianças quanto matemáticos podem afirmar que $2+3=3+2$, mas uma criança que apresenta como justificação a alternância dos dedos de suas mãos e os matemáticos que recorrem à propriedade comutativa da adição de números naturais produzem conhecimentos diferentes para $2+3=3+2$, porque suas justificações são diferentes.

Ao longo das formações das professoras entrevistadas, elas vivenciaram vários acontecimentos, mas nem todos as tocaram ou as marcaram, nem tudo se transformou em experiências. São experiências tudo o que lhes acontecem, passam-lhes e irão Ihes transformar, configurando a maneira delas de ser, conforme nos fala Larrosa Bondía (2002). Tendo o MCS como pressuposto metodológico de pesquisa, considera-se que as produções de significados das pedagogas foram a partir do que elas consideraram impactantes e as afetaram no momento das entrevistas sobre seus processos formativos e suas práticas docentes, podendo ser visto como produção de conhecimentos sobre esses processos e práticas.

As entrevistas foram semiestruturadas, cujo roteiro foi elaborado utilizando cinco temas: (1) Docência; (2) Crenças com relação à Matemática e à Educação Matemática; (3) Relação com a Matemática e professores de Matemática na Educação Básica; (4) Relação do Curso de Pedagogia com a Matemática; e, (5) Relação docência e formação universitária². Esses temas foram contextualizados em determinadas situações ou então contiveram perguntas direcionadoras para que as entrevistadas pudessem falar sobre eles quando somente o tema não se mostrava suficiente para que pudéssemos conhecer essas professoras, 
tentando compartilhar um espaço comunicativo, que ocorre quando modos de produção de significados são compartilhados, ou seja, compartilhar interlocutores, "[...] que, acredito, diria o que estou dizendo com a justificação que estou produzindo" (LINS, 1999, p. 88).

O MCS tem se constituído como referencial à realização de análises das entrevistas, uma vez que há teorizações envolvendo formação de professores com o MCS e possibilitando leituras finas de processos de produção de significados, o que Lins $(1999,2012)$ chamou de leitura positiva e leitura plausível. Nesta pesquisa, procurou-se fazer essas leituras, sendo a primeira mais específica, no momento de entrevistas, quando há interação de modo efetivo, pois, na leitura positiva, há uma busca por "[...] mapear o terreno ao mesmo tempo que trata de saber onde o outro está" (LINS, 2012, p. 24) e não onde ele poderia estar ou o que falta para ele, em termos de informação ou reflexão, por meio da tentativa de compartilhamento de interlocutores - direção na qual se fala. E a leitura plausível é feita quando não há interação de modo efetivo, podendo ser caracterizada do seguinte modo:

[...] Toda tentativa de se entender um autor deve passar pelo esforço de olhar o mundo com os olhos do autor, de usar os termos que ele usa de forma que torne o todo de seu texto plausível e é aqui que devemos prestar atenção às definições que um autor propõe (LINS, 1999, p. 93).

As noções do Modelo do Campo Semântico (MCS) abordadas aqui são as utilizadas à realização dessa pesquisa, outras podem ser vistas em Lins (1999, 2012) ou em Paulo (2020). No decorrer do artigo, outras noções do MCS serão explicitadas nas discussões propostas. Cabe ressaltar que ainda são incipientes as pesquisas realizadas de forma sistemática envolvendo a formação de pedagogos(as) em relação à Matemática sob a ótica do MCS (exemplos: JULIO; SILVA, 2018; SANTOS; SANTOS, 2018), ainda que Romulo Campos Lins tenha produções voltadas aos anos iniciais do Ensino Fundamental (LINS, 2014; LINS; GIMENEZ, 1997; LINS; SILVA, 2006).

\section{As Disciplinas de Matemática na Educação Básica}

Considera-se que a formação de pedagogos(as) não se inicia somente no ingresso ao curso superior. Curi (2005) e Nacarato, Mengali e Passos (2009) falam que muitas crenças constituídas pelos(as) pedagogos(as) são em razão dos(as) professores(as) que já tiveram na Educação Básica e que isso impacta em suas atuações profissionais. De fato, os(as) futuros(as) pedagogos(as) passam mais tempo tendo aulas de Matemática na Educação Básica do que no Ensino Superior e pode ser que os exemplos da educação matemática no primeiro espaço sejam mais fortes do que os da formação universitária.

Nacarato e Passeggi (2013), Julio e Silva (2018) e Kirsch e Cunha (2014) são exemplos de autores(as) que pesquisaram nesta direção. Julio e Silva (2018), por exemplo, analisaram, com base no MCS, narrativas escritas e orais produzidas por futuras pedagogas, visando entender a forma como as experiências com a Matemática, anteriores ao ingresso na universidade, podem influenciar suas concepções e atitudes frente às disciplinas de Matemática. Eles notaram que a formação matemática da Educação Básica deixou marcas profundas, como foi o caso da tabuada ser utilizada para punição ou constrangimento, um passado marcado, na maioria das vezes, por experiências ruins e dificuldades, ao mesmo tempo em que a Matemática vivenciada fora da escola foi narrada como importante e sem problemas nas 
atividades cotidianas. Já Kirsch e Cunha (2014, p. 15), ao observar e entrevistar as alunas do curso de Pedagogia da Universidade do Estado de Mato Grosso (UNEMAT), afirmaram que, "[...] enquanto algumas delas não possuem dificuldade com a disciplina de Matemática e sempre a compreenderam durante toda a vida escolar, outras possuem traumas com relação à disciplina, que carregam por toda a vida por nunca a compreenderem".

Em relação às entrevistas realizadas ${ }^{3}$, um primeiro aspecto a mencionar são as lembranças da Educação Básica, em que ocorreram demarcações de posturas sobre Matemática:

Na época que eu estudava, ia bem em matemática, até prefiro mais matemática do queo português, na verdade. [risos]. [...] Eu sempre participava da Olimpíada de Matemática, era divertido também. [Trecho de entrevista com a professora Luciana].

Muitas coisas assim eu não lembro, né, porque eu não sou muito fã da matemática. [risos] [fala em tom mais baixo]. [Trecho de entrevista com a professora Vera].

Eu prefiro português [...]. Lembro, e no Fundamental 2, mais ou menos no sexto e sétimo ano, eu tive muita dificuldade, isso eu lembro, nossa eu odiava. [...]. Mas agora no Fundamental 1 eu gostava muito, nossa eu lembro, no quarto ano, eu adorava. No Ensino Médio também, eu conseguia ir bem. [...] A época que eu mais gostei de matemática foi no terceiro e quarto ano. [Trecho de entrevista com a professora Angélica].

Eu não tenho um grande amor por matemática não, não é minha preferência [...]. Lembro, mas não com muita alegria. [...] A matemática foi difícil, tirando, assim, até meu primeiro, segundo ano que era bem básico. [Trecho de entrevista com a professora Patrícia].

[...] quando eu estudava, tinha dificuldade em matemática, tinha dificuldade nas ciências exatas, então na minha vida particular, não é uma coisa que é prazerosa. [...] Nossa, quando eu estava na escola, nunca gostei [de matemática], sempre tive dificuldade, até pelo que eu gosto de redação, de leitura. [Trecho de entrevista com a professora Maria].

Eu adoro matemática, [...] não lembro o nome do professor, mas eu me lembro da aula, adorava aqueles probleminhas tipo: se Marcelo comprou 3 bananas e perdeu duas no caminho, então quantas bananas ele ficou. [...] eu lembro que eu sempre queria ser a primeira a responder [...]. Mas eu acho que desta parte da matemática eu me lembro mais assim, que eu mais gostava, acho que primeiro, segundo ano deveria ser, essa idade que eu estou te falando. [Trecho de entrevista com a professora Ana].

As professoras Luciana e Ana falaram sobre a preferência para Matemática, enquanto Vera, Patrícia e Maria disseram não preferir Matemática. A professora Angélica, apesar de preferir português, relatou momentos que gostou de Matemática. Nessas lembranças, as professoras trouxeram mais falas sobre os anos iniciais do Ensino Fundamental do que sobre as outras etapas de escolaridade. Dentre os motivos de gostar ou não gostar de Matemática, um deles foi abordado pela professora Vera como sendo ela mesma, exemplificada pela fala:

Eu acho que nunca fui muito da área da matemática, porque os professores que eu tive foram bons mesmo, mas eu não tinha muita relação com a disciplina, nunca tive. [Trecho da entrevista realizada com a professora Vera].

${ }^{3}$ Todos os nomes das entrevistadas são nomes fictícios, para que a identidade delas seja preservada. 
Esta professora enfatizou, em mais de um momento nas entrevistas, que tem boas lembranças de suas professoras e elas eram muito boas, tanto as dos anos iniciais quanto as dos anos finais, sendo que uma delas trabalhava com Matemática por meio de músicas.

Na pesquisa de Julio e Silva (2018), também houve o caso de uma graduanda se colocar como responsável por não gostar de Matemática. A maior culpabilização dos professores, para esses autores, "[...] mostra o quanto os alunos não se colocam e nem são colocados como sujeitos da aprendizagem, o que talvez faça com que eles não se sintam responsáveis pela sua produção de conhecimentos" (JULIO; SILVA, 2018, p. 1022).

Outro motivo abordado pelas entrevistadas para não gostar de Matemática foi seus(suas) professores(as). A professora Angélica, por exemplo, fala que teve dificuldade no sexto e sétimo anos devido à professora, por ela não dominar o conteúdo e nem ser cativante:

[...] mas foi um ano que foi uma professora também que não dominava muito o assunto, é aquela coisa, se o professor não cativa e se você não gosta daquela matéria. [...] AA professora só passava na lousa, não tinha aquela didática para explicar. [...] A época que eu mais gostei da matemática foi no $3^{\circ}$ e $4^{\circ}$ ano, [...] acho que as professoras também gostavam, então elas dominavam mais, então foi uma época gostosa. Elas davam muitas atividades, no quarto ano eu tive uma professora que fazia muito isso, atividade para fora, então ela fazia muito jogo no chão, ela dava isso que eu te falei de somar, então eu gostava muito, porque ela fazia este lúdico. [Trecho de entrevista com a professora Angélica].

No trecho citado, a entrevistada menciona a questão do conteúdo, mas trouxe um elemento interessante para falar de uma professora que gostava de Matemática: o modo como ela lidava com o conteúdo e sua metodologia mais voltada ao lúdico. O lúdico também foi apontado como uma boa lembrança para a professora Ana, que gosta de Matemática:

[...] eu ainda lembro bastante das minhas aulas de matemática, eu lembro de alguns professores, [...] era bem gostoso, dinâmico, era lúdico, era com jogo, com brincadeira, muitas vezes saía de dentro da sala, as que eu me lembro, pode ser que eu me lembre só das aulas legais, era gostoso, eu lembro bastante coisa, mas eu não sei se é por eu gostar mais de matemática eu lembro mais das aulas de matemática e algumas de história. [...] [Trecho de entrevista com a professora Ana].

As metodologias dos(as) professores(as) e suas posturas com os(as) alunos(as) foram pontos importantes para não gostar de Matemática:

[...] em 1978 eu entrei no primeiro ano, era totalmente diferente o ensino, entendeu, era com quadro [...] e a matemática era só isso, é 1, 2, 3, 4, 5, você fazia, copiava, copiava, até você decorar os números e o desenho dos números, e você dividia porque era prático, então você aprendia a regra e fazia, mas você nem sabia o que aquilo significava, que cada um teria aquela quantidade de alguma coisa ou a multiplicação você multiplicava, porque era aquilo, [...] era como se fosse algo mágico, então $2 \times 6$ dá 12 e pronto e ao contrário também dava, $6 \times 2$ dá 12 , você vai dividir 12 por 2 você vai ter 6, pronto, entendeu, você fazia isso e tudo dava certo, então eu não tinha o porquê de entender, eu não consigo compreender, eu fui compreender divisão e que 10 [risos] era 10, 10 coisas, que era 10 quantidades de alguma coisa, eu já tinha quase 18 anos, porque até lá era no automático. E minhas notas eram ridículas, só não eram ruins em física e química, porque a maneira como o professor explicava eu encontrei sentido. [...] então, para mim foi muito difícil. [...] tirando, assim, até o meu primeiro, segundo ano que era bem básico, mas você fazia a conta automática, não tinha erro, 
colocava lá, $13+14=27$, pronto, estava certo, e agora, a professora enchia de conta no quadro, eu fazia, olha que beleza, acertou tudo, mas eu não tinha noção que $3+4$ dava 7 , porque 7 coisas, dava 7 porque era 7. [...] Porque às vezes dá impressão que a gente era meio retardado, eu não era retardadinha não, é que era a maneira como era explicado [...], era aquilo, a gente tinha que obedecer e pronto, a gente não podia reclamar, então você fazia, estava certo, ótimo, parabéns, não estava, era reguada, chamado de burro, então, você queria estar certo, você fazia no automático, sem saber o que você estava fazendo. [Trecho de entrevista realizada com a professora Patrícia].

A professora Patrícia, em sua época de escolarização, teve contato com uma matemática abordada de forma tradicional, na qual predominava o automatismo, não sendo explicado o porquê das coisas, situação também narrada pela professora Maria, que, ao contrário do que foi dito pela professora Patrícia, é mais nova que ela e também fala sobre uma abordagem tradicional da matemática, sem explicações do significado do que estava sendo feito, era aquilo e pronto:

[...] na época que eu estudava não tinha essa coisa do lúdico, de mostrar na prática como funciona, a fórmula é essa, então é tal, então é isso, porque dá isso, acabou, então muitas vezes eu ficava, nossa, gente, porque a porcentagem é assim. [...] Eu acho assim, que além de eu não gostar, não foi uma coisa que eu me identificava, o ensino era muito tradicional ainda. [Trecho de entrevista realizada com a professora Maria].

É importante dizer que, até mesmo quem gostava e ainda gosta de Matemática, como foi o caso da Luciana, fala sobre a metodologia tradicional do(a) professor(a):

[...] a minha professora era boa até, no terceiro ano ela foi muito boa, mas no começo, assim, principalmente, no fundamental, assim, eles são muito tradicionais, as vezes né, passa só aquele conteúdo e você tem que absorver aquilo, tem que entender. [...] Mas os meus professores foram bons [...] aquilo que eles passavam eu conseguia absorver. [...] A maioria era mais tradicionalista, no ensino médio nem tanto, foram mais assim, mostrava na prática tudo, até eu lembro que, uma vez a professora se dispôs depois do horário, no horário contrário, quem tivesse interesse em estar realizando um projeto, para estar desenvolvendo um projeto de matemática, a matemática em si, também [...]. [Trecho de entrevista com a professora Luciana].

Quanto às metodologias, foi feita uma distinção entre o lúdico e o cotidiano e o ensino tradicional, com a crença de que, se o ensino fosse lúdico ou mais voltado para o cotidiano, poderia ter sido melhor para algumas entrevistadas. Uma professora que vivenciou o ensino tradicional, e ainda assim gostava de Matemática, é um exemplo que contribuiu para questionar as metodologias de ensino, diferentes da tradicional, como mais eficazes para o ensino e a aprendizagem da Matemática. Lins (1999) contribui para essa discussão trazendo duas posturas educacionais, sendo a segunda mais coerente ao MCS. A primeira (E1) é aquela em que o(a) professor(a) acha que já sabe quem é o(a) aluno(a), e por isso usa os materiais de um jeito, desenvolvendo suas práticas a partir desse(a) aluno(a) que supõe já conhecer, antecipando-o(a), buscando maneiras eficientes para fazer acontecer o que já sabe que naturalmente deveria acontecer; neste caso, a metodologia de ensino vem antes, ou seja, um(a) professor(a) elege uma metodologia que ele considera eficaz para que a aprendizagem possa ocorrer. A segunda postura (E2) é aquela em que o(a) professor(a) não sabe como o(a) aluno(a) é, precisando ir até ele(a) para falar com ele(a), saber onde ele(a) está, criando uma interação, um espaço comunicativo compartilhado. Nesta postura, 
a metodologia vem depois, primeiro o(a) professor(a) está interessado em saber onde o(a) aluno(a) está para, depois, pensar na metodologia que utilizará em sala de aula, tendo em vista seus(suas) alunos(as) e sua intenção didática. Uma citação clássica da postura E2 é:

Não sei como você é; preciso saber. Não sei também onde você está (sei apenas que está em algum lugar); preciso saber onde você está para que eu possa ir até lá falar com você e para que possamos nos entender, e negociar um projeto no qual eu gostaria que estivesse presente a perspectiva de você ir a lugares novos (LINS, 1999, p. 85).

Voltando a falar sobre a postura do(a) professor(a) em sala de aula, foi mencionado pela professora Patrícia a rigidez de sua professora, que batia com a régua na mesa caso não respondesse corretamente o que ela estava perguntando. Esta professora menciona em outro momento da entrevista as reguadas na mesa se não decorasse a tabuada, demonstrando grande rancor pela situação de decorar a tabuada. A professora Ana marca uma diferença interessante quanto ao impacto que as posturas de suas professoras tiveram sobre ela, falando que gosta de Matemática, porém, uma professora por ser, em seu ponto de vista, grossa, julgar os alunos e ser sem paciência, acabou levando-a a não aprender Matemática, indo mal na disciplina desta professora, enquanto na disciplina da outra professora, que também trabalhava Matemática, ela ia muito bem e gostava, pois esta professora era boa e a estimulava:

[...] tinha uma professora que eu não gostava, eu achava que ela era grossa talvez para falar, quando a gente não a entendia não tinha certa paciência para explicar de novo [...] então com a [Professora A] eu ia muito mal e com a outra eu ia muito bem, e tipo as duas eram matemática, mas assim se eu fosse fazer a mesma coisa da [Professora A] com a outra professora eu sabia fazer, mas com ela [Professora A] falando na minha cabeça eu não sabia fazer, não sei se era uma coisa minha com ela, que eu não conseguia, ou se realmente tinha alguma coisa da parte dela [...] Eu acho que ela [Professora A] era muito brava, sempre gritando, não gritando assim, eu acho que mais sem paciência assim [...]. [Com a outra professora] eu lembro que era gostoso, era bom, passava na lousa, todo mundo queria resolver, era motivante sabe, para a gente conseguir resolver sozinho $e$ dela não [Professora A], parecia que era tipo uma obrigação resolver, não uma coisa sabe, que estimulava a gente a pensar e resolver, o dela além de ser uma obrigação, parece que quando não conseguia, ela julgava por não ter conseguido, não sei se é uma percepção minha. [...] Só com ela [Professora A] que não [não ia bem], com a [outra professora] eu ia bem, era tipo assim 5 e 10, que era muito diferente, a diferença era gritante. [Trecho de entrevista com a professora Ana].

Nacarato (2010) estabelece uma relação entre professores(as) e as disciplinas de Matemática dizendo que, quando o(a) professor(a) é colocado(a) no centro da atividade educacional, sendo aquele(a) que transmite o conteúdo, e o(a) aluno(a) aquele(a) que recebe esse conteúdo, o(a) aluno(a) estabelece muito mais uma relação com o(a) professor(a) do que com o conteúdo e, dessa forma, a figura do(a) professor(a) fica mais marcante nas lembranças que são trazidas. Pode-se ler a postura colocada por Nacarato (2010) como E1, na qual o(a) professor(a) já tem um(a) aluno(a) idealizado(a) e irá falar as coisas para que este(a) cumpra seu destino, pois já sabe quem é ele(a). 
Devido aos cenários vivenciados na Educação Básica, em relação à Matemática e à docência em Matemática pelas pedagogas, elas ingressaram no curso de Pedagogia e se depararam com a(s) disciplina(s) de Matemática, gerando diferentes expectativas que foram vivenciadas de diferentes formas, como pode ser visto a seguir.

\section{Expectativa quanto à(s) Disciplina(s) de Matemática no Curso de Pedagogia}

Como já mencionado, são muitas as possibilidades de atuação de pedagogos(as), podendo fazer com que as disciplinas denominadas conhecimento específico, como é o caso da Matemática, sejam poucas e tenham carga horária reduzidas. Pesquisas como as de Curi (2005) e Gatti e Nunes (2009) apontam que o número reduzido de disciplinas, a baixa carga horária e a ênfase nas metodologias de ensino (o como ensinar), em vez do conteúdo (o que ensinar), podem fazer com que os(as) pedagogos(as) sejam formados(as) sem saber ou ter segurança sobre as disciplinas que ensinarão. Esse cenário se junta a um cenário de vivências de futuros(as) pedagogos(as) com as disciplinas de Matemática na Educação Básica, que geram expectativas. Por isso, considera-se que conhecer os(as) futuros(as) pedagogos(as) e, em particular, suas expectativas, é importante no processo formativo.

Um aspecto para esse conhecimento é a vivência do estranhamento, na qual existe para nós, formadores(as) de professores(as), algo que é natural e gostamos, mesmo que estranho algumas vezes, como algumas noções matemáticas, e, do outro lado, os(as) futuros(as) pedagogos(as) que, muitas vezes, podem não gostar de Matemática e veem certas noções matemáticas que, nós, formadores(as), dizemos e que não pode ser dito para eles(as) (LINS, 2004; OLIVEIRA, 2011). O estranhamento possibilita o exercício do descentramento, outra noção do MCS, que está ligada à tentativa de o(a) professor(a) se colocar no lugar de seus(suas) alunos(as) de forma a evitar naturalizar certos modos de produção de significados (OLIVEIRA, 2011) para a docência e as noções matemáticas, que poderiam impossibilitar o(a) professor(a) de conseguir ler o estranhamento que acontece em sua sala de aula.

Levando em consideração as professoras Luciana e Ana, que gostavam de Matemática e em suas lembranças a colocaram como algo bom, vê-se que a professora Luciana tinha expectativa de aprender mais Matemática, sendo que ambas as professoras pensaram que seria ensinado o que cada etapa da escolarização precisa saber de Matemática, aprendendo como trabalhar os conteúdos de cada uma delas. A professora Ana é enfática nesse sentido pois, por diversas vezes, falou sobre isso relatando, também, ter uma expectativa positiva ao saber que teria a disciplina de Matemática, pois sempre foi uma das matérias de que mais gostou:

Então, eu pensava que era uma coisa, porque assim, na faculdade, a gente só vai ver mesmo na rotina da sala de aula [...] eles não ensinam o que a gente vai passar para as crianças, têm muita história da matemática, como que surgiu a matemática, de onde que veio tudo, mas eles não explicam o que a gente vai ensinar na Fase 1, o que que vai ser ensinado na Fase 2, às vezes isso falta um pouco entendeu, a maneira de estar passando a matemática mesmo, isso fica muito na teoria, isso na faculdade fica bem teórico. [Trecho de entrevista com a professora Luciana].

Eu adorei. [...] Sim, eu estou falando do como ensinar, o que ensinar, não em relação aos conteúdos, por exemplo, no primeiro ano você vai ensinar isso e eles vão sair sabendo isso, eu não me lembro de ter tido nada desta parte, não só em relação a matemática, mas de todas as disciplinas, mesmo no infantil, no fundamental, nunca, tipo assim, o que ensinar, tipo a gente tinha aula lá, aí por exemplo a gente vai ensinar isso, isso, isso, mas 
assim, para que série você vai dar isso [...] eu acho que deveria, não sei se é a faculdade que eu fiz, mas eu acho que deveria ser claro para a gente, ao longo da faculdade saber o que dar para cada série, se preparar, não só para mim. [...] [Trecho de entrevista com a professora Ana].

Ambas as professoras falaram que saíram da faculdade sem saber o que ensinar em cada etapa da escolaridade. Isso está relacionado não somente ao conteúdo ou à metodologia, como as discussões envolvendo a formação de pedagogos(as) enfatizam, mas ao currículo de disciplinas de Matemática, o que é preconizado em cada etapa de escolaridade. A professora Ana, em particular, disse sair da faculdade sem se preparar, ainda no âmbito do currículo. Romulo Campos Lins fazia uma distinção entre preparar aulas e se preparar para as aulas, podendo contribuir para teorizações sobre formação de professores que ensinam Matemática. Essa distinção foi teorizada em Julio e Oliveira (2018), tendo as noções de estranhamento e descentramento como chaves, ao enfatizar que se preparar para as aulas envolve lucidez matemática, ou seja, saber mais Matemática no sentido de

[...] um entendimento maior de como os conteúdos são organizados e constituem uma disciplina, passando por problematizações desses conteúdos que envolvem também a prática docente na escola básica, e considerando que, mesmo dentro dessa disciplina, podem ser produzidos diferentes significados para o que pode parecer ser a mesma coisa. A lucidez matemática envolve também confiança matemática, que seria uma atitude de não fugir de situações que envolvem a Matemática e nem as tomar como naturais (VIOLA DOS SANTOS, 2012) no trabalho docente. (JULIO; OLIVEIRA, 2018, p. 120).

Preparar-se para a docência significa, também,

[...] a tentativa de antecipar o que os alunos podem dizer a partir de resíduos de enunciação com os quais se depararão em sala de aula, pensar em decisões que podem ser tomadas; frente a diferentes produções de significados dos alunos e tendo em vista os objetivos de uma aula, como, enquanto professor, devo agir e que decisões posso tomar no momento da aula (JULIO; OLIVEIRA, 2018, p. 115).

É possível afirmar que se preparar para a docência e a formação de pedagogos(as), a partir do MCS, não ocorre somente em termos de saber mais conteúdo, mais metodologias e o currículo escolar, mas na vivência de diferentes modos de produção de significados para conteúdos, metodologias, currículos e situações de sala de aula.

Para quem não gostava de Matemática, houve diferentes expectativas quando foram cursar a(s) disciplina(s) de Matemática na graduação. A professora Angélica, que prefere português e relatou momentos de que gostou de Matemática disse: "Aí não tinha como escapar né [na faculdade] [...] A faculdade me ajudou [...]". (Trecho de entrevista com a professora Angélica).

As professoras Vera e Patrícia viram na faculdade uma oportunidade de aprender como ensinar Matemática, sendo que a professora Patrícia pensou que iria aprender Matemática, também, tendo, contudo, decepcionando-se.

Quando eu vi que teria disciplina de Matemática eu achei muito bom [...] eu vou ter na faculdade uma disciplina que me ensina como ensinar, então eu achei legal sim, ótimo ter o curso na faculdade, o curso foi muito bom. [Trecho de entrevista com a professora Vera]. 
Eu falei assim, eu achei interessante, porque na minha concepção eu achei que eu ia aprender matemática, que eu ia aprender a ensinar, entendeu, e fiquei meio decepcionada porque não foi isso. [Trecho de entrevista com a professora Patrícia].

Diferenciando-se das outras, a professora Maria se preocupou ao saber que teria Matemática, pois era uma matéria que ela tinha dificuldade:

Eu já falei: 'Nossa!' [risos]. Eu esperava, porque são diversas as disciplinas que a gente tem que trabalhar, mas eu já falei: 'Nossa Senhora, como é que eu vou fazer, se é uma coisa que eu tenho dificuldade, como é que eu vou ensinar, como é que eu vou passar para frente?' Eu tive essa preocupação no início. [Trecho de entrevista com a professora Maria].

Para as pedagogas que não gostavam de Matemática, houve falas delas no sentido da tentativa de superação, pois as disciplinas poderiam se constituir como um momento de aprendizagem, além da preocupação por se depararem com algo necessário à formação em Pedagogia, mas da qual não gostavam na Educação Básica.

Com todas essas expectativas, o que se lê, no decorrer das entrevistas, são críticas sobre a(s) disciplina(s) de Matemática cursada(s). A professora Ana, por exemplo, mesmo gostando de Matemática e tendo expectativas de aprender o que deveria ser ensinado em cada etapa da escolarização, fala da graduação ser bem diferente da prática; a professora Patrícia fala nessa mesma direção.

Então, assim, através do que eu aprendi lá, na faculdade foi muito pouco, eu acho que a Pedagogia deixa muito falho essa parte, eu acho que a Pedagogia deveria ser mais focada, não só nos livros, nas teorias, deveria haver uma prática pedagógica diferenciada. [...] Foi algo inexpressivo, não fez a menor diferença na minha vida. [Trecho de entrevista com a professora Patrícia].

[...] a faculdade em si é bem diferente da prática, porque, por mais assim que o professor tenta passar a experiência dele, tenta passar a forma de trabalhar dele, é diferente da nossa, e cada sala vai ser diferente da outra sala, então eu acho que mesmo que a gente faça estágio, na hora que a sala é da gente, que a gente vai programar, planejar, é diferente, então acho que a faculdade, não sei se prepara realmente a gente para dar aula, não só de matemática, mas eu acho que em tudo, não dá para a faculdade mudar alguma percepção assim, porque a gente vai ter a percepção mesmo depois. [...]. [Trecho de entrevista com a professora Ana].

As professoras, ao relacionarem a docência com a formação universitária, falam no sentido de uma formação que não contribuiu à docência em sala de aula. O que se entende dessas falas é que foi uma docência voltada para uma realidade já dada (teoria) ou vivida por um professor, o que, de novo, o MCS se apresenta como potente ao enfatizar a leitura dos(as) alunos(as) para conhece-los(as) e lidar com suas diferenças e, a partir disso, planejar atividades que possam se tornar convite para diferentes aprendizagens desses(as) alunos(as), o que pode ser feito na graduação pela vivência de diferentes situações envolvendo Matemática e a docência de Matemática que possibilitem diferentes modos de produção de significados.

As próximas falas enfatizam a prática profissional como formadora, porque é nela que as coisas acontecem, enquanto no Ensino Superior são situações antecipadas. 
A prática é totalmente diferente, a gente começa a ver um pouco no estágio, mas a gente só vai ver mesmo quando está numa sala de aula, e enxerga aquela realidade. Às vezes, o que é passado na faculdade, [...] então a gente tem que saber se adaptar a essa realidade, e muitas vezes isso não é falado na faculdade né [...]. [Trecho de entrevista com a professora Luciana].

Olha, a formação pedagógica é importante, só que eu acredito que a experiência que a gente adquire na sala mesmo, no espaço escolar, conta muito, então, eu acho que a experiência que a gente tem, ela acaba sendo mais válida do que o próprio curso. [...] Acho que o curso não contribuiu muito para a forma como eu lido com a matemática, apesar do curso ter sido bom, [risos] ele poderia ter sido um pouco melhor, assim, que eu te falei, teve aulas mais práticas, mas poderia ter tido mais, ele dava o teórico e depois a prática, só que assim, é muito mais o teórico, o espaço para a prática sempre era menor, eu acredito que poderia ter sido um pouco mais. [Trecho de entrevista com a professora Vera].

Olha, eu falo que a prática vale mais que a formação, só que a gente tem que passar pela formação, mas é a prática que vai te fazer um bom ou não bom profissional, então assim a formação ajuda muito, precisa, os professores não podem ficar estagnados, eles têm que estar sempre renovando, mas a prática que vai te fazer amadurecer mais. [Trecho de entrevista com a professora Angélica].

Um grande diferencial do MCS é deixar seus pressupostos claros. É inegável o papel formador da prática, mas antecipações de situações nas práticas formativas, de acordo com o MCS, pode se constituir como possibilidade para lidar com diferentes situações que podem ocorrer em sala de aula, ainda que situações não previstas possam ocorrer. Explicitar isso na formação, tendo o MCS como um referencial, talvez contribua para mudar a visão dos processos formativos no curso de Pedagogia.

Almeida e Lima (2012, p. 461), em seu estudo, falam sobre essa relação que o futuro professor tem com a Matemática e qual a importância da graduação nesse processo. Para os autores, o curso de Pedagogia precisa ser libertador e tentar remover o "muro de desafeto" que distancia os(as) futuros(as) professores(as) desta área, pois, caso contrário, isso pode se estender para os(as) alunos(as) desses(as) professores(as). Nas transcrições anteriores, as professoras Vera, Patrícia e Maria, que não gostavam de Matemática, tinham expectativas de aprender, pois não era uma área que dominavam, porém, essas expectativas não foram atendidas.

Para a tentativa de remoção do "muro de desafeto" com a Matemática, algumas práticas fundamentais, da perspectiva assumida, são a leitura dos(as) futuros(as) pedagogos(as), da produção de conhecimento deles(as), suas experiências na Educação Básica e suas expectativas, pela vivência e aceitação de estranhamentos e pelo exercício do descentramento, para que os(as) formadores(as) possam se aproximar deles(as) e tentar executar um projeto que amplie o entendimento deles(as) de Matemática e de ensino de Matemática. Lins (2005, p. 120) afirmou que "[...] o centro da atividade profissional de um professor, seja de que disciplina for, é ler os alunos e tomar decisões sobre o que está acontecendo e como seguir". Considera-se, com base no MCS, de fundamental importância para os(as) formadores(as) essa leitura, pois isso pode ajudar a tentar estabelecer um espaço comunicativo com eles(as) e um projeto de formação que, apesar de poucas disciplinas e com carga horária reduzida, esteja presente um projeto comum de aprendizagem Matemática e discussões sobre a docência envolvendo Matemática a partir de diferentes modos de produção de significados. 


\section{Considerações Finais}

Neste artigo foram trazidos, em um primeiro momento, os aspectos sobre a formação do(a) pedagogo(a), profissional polivalente que terá que lidar com várias disciplinas na sala de aula, inclusive a Matemática. Abordou-se que a formação e a prática do(a) pedagogo(a) em relação à Matemática têm sido uma questão cada vez mais discutida e pesquisada, sendo incipientes as pesquisas envolvendo a formação de professores(as) que ensinam Matemática na Educação Infantil e nos anos iniciais do Ensino Fundamental, tendo o MCS como perspectiva teórica. Foi apresentada uma leitura das falas das pedagogas iniciantes, a partir das entrevistas realizadas com elas, sobre suas vivências com as disciplinas de Matemática da Educação Básica e suas expectativas quando foram cursar a(s) disciplina(s) de Matemática no curso de Pedagogia e se essas expectativas foram atendidas.

A trajetória escolar pode ter influência na prática docente do(a) pedagogo(a) e até mesmo em sua formação universitária. Pelas falas das pedagogas, conclui-se que algumas preferiam Matemática e outras não. Dentre os motivos de gostar e não gostar de Matemática, uma professora se coloca como responsável por não gostar, em outro caso o(a) professor(a) é colocado(a) como o(a) responsável pela entrevistada não gostar, com diferentes motivos. Diante disso, percebe-se que as relações que as pedagogas estabeleceram com os(as) professores(as) de Matemática impactam em sua aprendizagem.

Diante disso, algumas professoras tinham diferentes expectativas com a(s) disciplina(s) de Matemática no Ensino Superior, sendo, por exemplo, aprender mais Matemática, aprender como ensiná-la, pensando que as dificuldades matemáticas seriam superadas na Licenciatura. Contudo, parecem não terem sido atendidas, devido às críticas que fizeram.

Tendo em vista as discussões realizadas, acredita-se que os cursos de Pedagogia têm um papel importante na mudança nos modos de ver a Matemática e a docência de Matemática de futuros(as) pedagogos(as), o que pode ser feito a partir do convite para a vivência de diferentes modos de produção de significado para a Matemática e a docência em Matemática, sendo importante, também, voltar seus olhares às expectativas dos(as) futuros(as) professores(as), para conhecê-los(as), tentar se colocar no lugar deles(as) e criar um espaço comunicativo com eles(as) na(s) disciplina(s) de Matemática em vez de antecipálos(as) e continuar reproduzindo posturas como a E1, que contribuem à manutenção do "muro de desafeto" com a Matemática que podem se estender em suas práticas profissionais.

\section{Referências}

ALMEIDA, M. B.; LIMA, M. G. Formação inicial de professores e o curso de pedagogia: reflexões sobre a formação matemática. Ciência \& Educação, Bauru, v. 18, n. 2, p. 451-468, 2012. DOI: https://doi. org/10.1590/S1516-73132012000200014.

BORBA, R.; CURI, E. Educação matemática na educação infantil e nos anos iniciais do ensino fundamental. Perspectivas da Educação Matemática, Campo Grande, v. 9, n. 21, p. 594-599, 2016. Disponível em: https://cutt.ly/wf0Vk9U. Acesso em: 16 set. 2020.

BRASIL. Conselho Nacional de Educação. Parecer CNE/CP No 5/2005: diretrizes curriculares nacionais para o curso de pedagogia. Brasília: CNE, 2005.

CURI, E. A matemática e os professores dos anos iniciais. São Paulo: Musa, 2005. 
FIORENTINI, D.; PASSOS, C. L. B.; LIMA, R. C. R. (org.). Mapeamento da pesquisa acadêmica brasileira sobre o professor que ensina matemática: período 2001 a 2012. Campinas: Unicamp, 2016.

GATTI, B. A.; NUNES, M. M. R. Formação de professores para o ensino fundamental: estudo de currículos das licenciaturas em pedagogia. Textos FCC, São Paulo, v. 29, p. 1-160, 2009.

JULIO, R. S.; OLIVEIRA, V. C. A. Estranhamento e descentramento na prática de formação de professores de Matemática. Boletim Gepem, Seropédica, n. 72, 112-123, 2018.

JULIO, R. S.; SILVA, G. H. G. Compreendendo a formação matemática de futuros pedagogos por meio de narrativas. Bolema, Rio Claro, v. 32, n. 62, p. 1012-1029, 2018. DOI: https://doi.org/10.1590/1980$4415 v 32 n 62 a 13$.

KIRSCH, R.; CUNHA, M. M. Relações entre a formação inicial de professores das séries iniciais e a prática pedagógica no ensino-aprendizagem da matemática. Revista Eventos Pedagógicos, Sinop, v. 5, n. 4, p. 14-24, 2014.

LARROSA BONDÍA, J. Notas sobre a experiência e o saber de experiência. Revista Brasileira de Educação, Rio de Janeiro, n. 19, p. 20-28, 2002. DOI: https://doi.org/10.1590/S141324782002000100003.

LINS, R. C. A formação pedagógica em disciplinas de conteúdo matemático nas licenciaturas em Matemática. Revista de Educação PUC-Campinas, Campinas, n. 18, p. 117-123, 2005. Disponível em: http://periodicos.puc-campinas.edu.br/seer/index.php/reveducacao/article/view/267. Acesso em 16 set. 2020.

LINS, R. C. O modelo dos campos semânticos: estabelecimentos e notas de teorizações. In: ANGELO, C. L.; BARBOSA, E. P.; SANTOS, J. R. V.; DANTAS, S. C.; OLIVEIRA, V. C. A. (org.). Modelo dos campos semânticos e educação matemática: 20 anos de história. São Paulo: Midiograf, 2012. p. 11-30. Disponível em: http://sigma-t.org/permanente/2012.pdf. Acesso em 16 set. 2020.

LINS, R. C. Monstros, matemática e significados. In: BICUDO, M. A. V.; BORBA, M. C. (org.). Educação matemática: pesquisa em movimento. São Paulo: Cortez, 2004. p. 92-120.

LINS, R. C. Por que discutir teoria do conhecimento é relevante para a educação matemática. In: BICUDO, M. A. V. (org.). Perspectivas em educação matemática: concepções e perspectivas. São Paulo: Editora da Unesp, 1999. p. 75-94.

LINS, R. C. Serve para alguma coisa saber para que 'serve' a matemática?: ou é melhor pensar sobre o que ela muda no mundo? Salto para o Futuro, Brasília, ano 24, boletim 10, p. 13-21, set. 2014.

LINS, R. C.; GIMENEZ, J. Perspectivas em álgebra e aritmética para o século XXI. Campinas: Papirus, 1997.

LINS, R. C.; SILVA, H. Frações: fascículo 4. In: PRÓ-LETRAMENTO: programa de formação continuada de professores dos anos/séries iniciais do ensino fundamental: matemática: fascículo do tutor e encartes. Brasília: Ministério da Educação, Secretaria de Educação Básica, 2008. Disponível em: http://portal.mec.gov.br/seb/arquivos/pdf/Proletr/tutormat.pdf. Acesso em: 10 set. 2020.

NACARATO, A. M. A formação matemática das professoras das séries iniciais: a escrita de si como prática de formação. Bolema, Rio Claro, v. 23, n. 37, p. 905-930, 2010. Disponível em: http://www. periodicos.rc.biblioteca.unesp.br/index.php/bolema/article/view/4298. Acesso em: 10 set. 2020.

NACARATO, A. M.; MENGALI, B. L. S.; PASSOS, C. L. B. A matemática nos anos iniciais do ensino fundamental: tecendo fios do ensinar e do aprender. Belo Horizonte: Autêntica, 2009.

NACARATO, A. M.; PASSEGGI, M. D. C. Narrativas autobiográficas por futuras professoras: representações sobre a matemática escolar. Revista de Educação PUC-Campinas, Campinas, v. 18, n. 3, p. 287-299, 2013. 
OLIVEIRA. V. C. A. Uma leitura sobre formação continuada de professores de matemática fundamentada em uma categoria da vida cotidiana. 2011. 207 f. Tese (Doutorado em Educação Matemática) - Universidade Estadual Paulista, Rio Claro, 2011. Disponível em: https://repositorio. unesp.br/handle/11449/102098. Acesso em: 10 set. 2020.

PAULO, J. P. A. Compreendendo formação de professores no âmbito do modelo dos campos semânticos. 2020. 294 f. Tese (Doutorado em Educação Matemática) - Universidade Estadual Paulista, Rio Claro, 2020. Disponível em: https://repositorio.unesp.br/handle/11449/191665. Acesso em: 10 set. 2020.

SANTOS, D. G. C.; LIMA, M. B. Formação de professores de matemática para as séries iniciais do ensino fundamental: breve panorama de pesquisa. In: CONFERÊNCIA INTERAMERICANA DE EDUCAÇÃO MATEMÁTICA, CIAEM, 13., 2011, Recife. Anais [...]. Recife: Comitê Internacional de Educação Matemática. Recife, 2011.

SANTOS, E. S.; SANTOS, J. R. V. Uma discussão da matemática do professor que ensina matemática nos anos iniciais do ensino fundamental. Boletim Gepem, Seropédica, n. 72, p. 38-51, 2018. DOI: https://doi.org/10.4322/gepem.2018.004. 